\title{
A VIAGEM PELA BARCA DE PEDRA
}

Ronaldo Ventura Souza ${ }^{1}$

RESUMO: O presente artigo trata do tema da viagem em A Jangada de Pedra, de José Saramago, tendo como base o ensaio de Octávio Ianni, “A metáfora da Viagem”. A viagem, no romance, surge como um meio de descoberta, reflexão e aprendizado, em que o caminhante descobre mais sobre o outro e sobre si mesmo.

PALAVRAS-CHAVE: Viagem; romance; personagem; Saramago

\begin{abstract}
The present work makes an analyze of the trip as theme in the Raft of Stone, of José Saramago, being based in the Octávio Ianni’s essay, “A metáfora da Viagem”. In this novel, the trip appears as a middle of discovery, reflection and learning, through which the traveler discovers more about the other and about himself.
\end{abstract}

KEYWORDS: Trip; novel; character; Saramago

\footnotetext{
${ }^{1}$ Mestre e doutorando em Literatura Portuguesa pela USP
} 
Octávio Ianni, em "A metáfora da Viagem”, mostra que a viagem, como realidade ou metáfora, faz-se presente na história, nas ciências sociais e na literatura. Ela aparece como um meio do homem conhecer a si e ao outro, pois "sob vários aspectos, a viagem desvenda alteridades, recria identidades e descortina pluralidades" (IANNI, 2000, p. 14). Desse modo, a viagem surge como um meio de descoberta, reflexão e aprendizado, pois o caminhante aprende sobre o outro e no contraponto com este aprende mais sobre si mesmo. Há vários tipos de viagem e o viajante pode ou não estar em movimento. Nesse sentido, podemos através da literatura nos aventurar pelo espaço e pelo tempo, conhecer reflexões sociais, históricas e antropológicas. E até entender mais sobre nós mesmos.

O tema da viagem se faz presente na história literária desde seus primórdios. Podemos citar aqui a Odisséia, de Homero, em que finda a Guerra de Tróia, o herói grego, Ulisses, inicia sua jornada de retorno a Ítaca. Porém, por desacato aos deuses, é condenado a vagar pelos mares antigos. Trata-se de uma viagem cheia de percalços, em que somente depois de muitas provas, o navegante consegue alcançar o seu destino. Na Eneida, de Virgílio, Enéias viaja até a península itálica, para se tornar o patriarca dos romanos, seu percurso não é menos cheio de obstáculos que o do grego. Dante caminha pelo mundo mítico da Divina Comédia, para que conhecendo a vida após a morte, volte a trilhar "a verdadeira via" e sua alma não se perca, seu itinerário corresponde o Inferno, Purgatório e Paraíso, e a aprendizagem resultante do contato com essas paragens do além-mundo é de suma importância para que o herói volte a trilhar o caminho correto da fé cristã. Em $O s$ Lusíadas, Vasco da Gama parte rumo as Índias, num percurso povoado por criaturas míticas, em que se revela a grandeza e sagacidade dos portugueses no início das grandes navegações. E por que não falar em Dom Quixote que, embevecido pelas leituras de novelas de cavalaria, resolver sair pelo mundo, aventurando-se como se fosse um cavaleiro andante numa época em que a ordem feudal dá lugar ao Mercantilismo. Nessas viagens, o herói é aquele que se inquieta e que interroga por cada coisa que encontra em seu caminho. Ulisses se prende ao mastro de seu navio para conhecer o canto das sereias. Dante interroga sobre cada condenado em seu trajeto pelo Inferno. Dom Quixote procura por sua amada Dulcinéia, que não passa de uma idealização de sua imaginação doentia. "A inquietação e a 
interrogação caminham juntas, sempre correndo o risco de encontrar o óbvio ou o insólito, o novo ou o fascinante, o outro ou o eu" (IANNI, 2000, p. 25). Nesse contexto também se insere o romance A Jangada de Pedra, de José Saramago, em que o tema da viagem surge como centro da narrativa, seja pelo fato de a própria península ibérica se desgarrar do continente europeu e se mover em direção ao sul, como que em busca de uma identificação maior, seja pela viagem das personagens principais que se deslocam de um ponto ao outro da península em busca de resposta para os acontecimentos incomuns que marcam a existência de cada um deles. E o herói ou heroína dessa história é "o caminhante que se põe a flutuar pelo mundo afora, de modo a desprender-se e despertar-se, distanciar-se e clarificar-se, mergulhar em sua reflexão e soltar a imaginação” (Idem, ibidem).

O deslocamento da Península Ibérica pode representar metaforicamente a condição cultural e política de Portugal e Espanha em relação a outros países da Europa no momento em que o romance foi escrito, período em que esses dois países passam a integrar a Comunidade Econômica Européia. Deste modo, o romance apresenta uma mensagem que corresponde ao posicionamento político e ideológico do autor, mas considerá-lo apenas nestes termos seria empobrecer a análise. Para Leyla Perrone-Moisés, os romances de Saramago, em princípio romances de tese, uma vez que repousam em convicções éticas e políticas do romancista, são mais que isso, "porque Saramago é, antes de tudo, ficcionista. (...) Sua dialética é a da criação literária, em que a criação não desemboca numa síntese positiva, mas desencadeia a lógica subversiva dos possíveis” (PERRONE-MOISÉS, 1999, p. 243). Este é o caso de A Jangada de Pedra. Nesse romance, a viagem que se apresenta como espinha dorsal nos deixa visualizar não apenas aspectos políticos, mas nos apresenta outros temas caros à cultura ibérica e ao cânone literário europeu. O romance faz citação de diversas obras literárias de suma importância para a cultura ocidental, como a Bíblia, as novelas de cavalaria, Dom Quixote, Odisséia, entre outras, criando assim uma relação de intertextualidade com essas obras.

A citação intertextual que se faz a Ulisses pode ser uma forma de inserir o romance nessa linha das viagens marítimas, como a realizada pelo herói da Odisséia e, além disso, remete a lenda de que esse ilustre navegante esteve em praias lusitanas, levando-nos a estabelecer paralelos entre a viagem do herói grego e a navegação da Península Ibérica, ambos a procura de um caminho: "Ainda que muito nos custe, já nos resignamos a que 
Ulisses não chegue à praia a tempo de encontrar a doce Nausicaa, mas ao menos se permita que o cansado mareante dê à costa na ilha dos Feácios, e, não podendo se essa, outra qualquer..." (SARAMAGO, 2001, p. 303). O velho tema da viagem marítima, tão caro a cultura ibérica, tem grande relevância nessa história. Segundo Horácio Costa, esse romance, "se atreve a retomar el viejo e dorsal tema de la vocación ibérica, de sendos resultados sea en el plano de la literatura y de la ensayística como en el de la historia" (COSTA, 1998, p. 156), pois aponta para o mar, inserindo-se numa tradição literária de que fazem parte obras como Os Lusíadas, de Camões ou Mensagem, de Fernando Pessoa: “e a massa de pedra e terra coberta de cidades, aldeias, rios, bosques, fábricas, matos bravios, campos cultivados, com a sua gente e os seus animais, começou a mover-se, barca que se afasta do porto e aponta para o mar outra vez desconhecido" (SARAMAGO, 2001, p. 43).

Outro tema também relevante é o da cavalaria andante. Dom Quixote, hora e outra, é lembrado pelo narrador, que parece nos querer apontar para semelhança entre a andança das personagens de a Jangada de Pedra e a desse cavaleiro solitário:

Joaquim Sassa olhou para fora, viu casas, árvores por cima dos telhados, campos rasos, adivinham-se alagadiços, os arrozais, é o suave Mondego, antes ele que uma penha agreste. Fosse esse o pensamento de Pedro Orce e à história infalivelmente viriam $\mathrm{D}$. Quixote e a sua triste figura, a quem tem e a quem fez, em couro, aos saltos como doido no meio dos penhascos da serra Morena, seria um desproposito trazer tais episódios da andante cavalaria a colação...(SARAMAGO, 2001, p.137)

E até a novela de cavalaria Amadis de Gaula é citada, num episódio em que o narrador compara o casal Joaquim Sassa e Maria Guaivara a Amadis e Oriana: "Esta manhã vi Amadis e Oriana, ela a cavalo e ele a pé...” (Idem, p. 237). Por vezes, as personagens são descritas, parodicamente, como cavaleiros andantes: “O condutor José Anaiço pensou que a amada estivesse em perigo, e, outra vez, cavaleiro andante, parou bruscamente o carro, saltou e foi acudir..." A paródia das novelas de cavalaria criam uma sensação de volta no tempo. Em um dado momento da narrativa é como se as personagens caminhassem por um cenário medieval e vivessem num mundo estranho ao século em que se dá a história. Isto resulta em uma sensação temporal caótica, as coisas fora do lugar, talvez, condizente com o cenário apocalíptico resultante do desligamento da grande massa de pedra do continente europeu. 
Como vemos, a Península Ibérica não é a única a se deslocar dentro do romance. Nessa grande barca de pedra, Joaquim Sassa, José Anaiço, Pedro Orce, Joana Carda e Maria Guaivara se vêem envolvidos em fatos insólitos que de alguma forma os relaciona com o desligamento dos países ibéricos do continente europeu. Em vista disso, eles se juntam em uma jornada, que a princípio visa buscar respostas para os acontecimentos, mas que continua sem um destino aparente, dado o caráter circular do ir e vir das personagens. Este movimento é como o da vida "vê-se-lhe o princípio mas não se lhe conhece o fim"(SARAMAGO, 2001, p. 22-3). E essa comparação pode estar relacionada com o que ocorre dentro do próprio romance, em que a viagem da Península tem um fim totalmente imprevisível, tal como o dos navegantes portugueses do século XV: "barca que se afasta do porto e aponta para o mar outra vez desconhecido" (Idem, p. 43). Podemos pensar, aqui, na definição dada por Lukács a respeito da personagem romanesca. Segundo ele, o conteúdo do romance "é a história da alma que sai a campo para conhecer a si mesma, que busca aventuras para por elas ser provada e, pondo-se à prova, encontrar sua própria essência" (LUCKÁCS, 2000, p. 91). A busca de autoconhecimento (ou de aventuras) é uma característica essencial das personagens de A Jangada de Pedra. Ao viajarem pela Península em movimento, elas anseiam, de certo modo, dar um sentido para as suas próprias vidas. Cada aventura representa uma experiência, que as modifica interiormente. Um grande exemplo disso são as relações amorosas. É na relação com Maria Guaivara que Joaquim Sassa sabe pela primeira vez o que é amar: "o meu problema é que não sei de quem gostar e como se faz para continuar a gostar" (SARAMAGO, 2001, p. 151) No encontro dos dois podemos notar como uma personagem se modifica na relação com a outra:

Não é bonita, pensou, mas também não é feia, tem as mãos gastas e fatigadas, não se comparam com as minhas que são de empregado de escritório em gozo de férias pagas (...) esta Maria Guaivara que tem uma maneira de olhar que não é olhar mas mostrar os olhos, veste escuro, viúva que o tempo já aliviou, mas que o costume e a tradição ainda enegrecem, felizmente brilham-lhe os olhos, e ali está a nuvem azul que parece não pertencer a esta casa, os cabelos são castanhos, e tem o queixo redondo, e os lábios cheios, e os dentes, ainda há pouco os vi, são brancos, graças a Deus, afinal essa mulher é bonita e eu não tinha reparado (...) se agora eu pudesse, Pedro Orce, dizia-te uma coisa, Que coisa me dirias, Que já sei de quem gostar... (SARAMAGO, 2001, p. 180-1). 
A primeira impressão que Joaquim Sassa tem de Maria Guaivara é a da pessoa que não sabe como gostar de outra pessoa. Porém, a medida que ele a observa sua percepção sobre ela se modifica. Trata-se de um descobrimento e Joaquim Sassa não encontra apenas sua nova companheira de viagem, mas algo que ele julgava não existir em si mesmo, a capacidade de gostar de alguém. E momentaneamente sua vida ganha um novo sentido. Conhecer Maria Guaivara significa para Joaquim Sassa conhecer a si mesmo. Assim, como empregado de escritório, terminada suas férias, ele deveria voltar aos seus antigos afazeres, porém escolhe ficar ao lado da mulher que acabara de conhecer.

No "curso da viagem há sempre alguma transfiguração, de tal modo que aquele que parte não é nunca o mesmo que regressa" (IANNI, 2000, p. 31). Dessa forma, as personagens centrais de A Jangada de Pedra se delineiam perante nossos olhos a partir do momento em que saem em busca de respostas para os acontecimentos singulares que ocorrem em suas vidas e que, de alguma forma, cria laços entre cada uma delas, unindo-as em um mesmo destino, que é comum ao dos outros homens, pois a caminhada que elas empreendem "rumo ao conhecimento transforma-se no caminho a ser empreendido por todo ser humano" (LOPONDO, 1998, p. 72). Como a lua, que leva a noite toda à procura do caminho, assim agem os viajantes desse romance, pois buscam um sentido para as suas vidas, diante dos fatos que os marcaram. E essa viagem, tanto física, quanto psicológica, representa a própria aventura que é a vida e que, no final das contas, é a ela que se refere o romance: o seu fim e o seu recomeço.

Maria Alzira Seixo, em Lugares de ficção em José Saramago, aponta a viagem como um tema constante na obra de Saramago. Segundo ela, a personagem saramaguiana se caracteriza como um homem regido pelas contradições de sua viagem sobre a terra:

e exprimindo em absoluto as contradições da incessante viagem do homem sobre a terra, a sua vida; com os outros; contra alguns outros, porque entre a verdade e a ficção se situa uma simulação que não é estética, antes rotura ética do conjunto social harmônico, e essa é toda a problemática do erro, da deformação, da anamnese, da possibilidade de conhecimento que permite a formação ideológica do mundo e a sua formulação artística em termos de representação (SEIXO, 1999, p. 39).

Dessa forma, a viagem no romance saramaguiano representa mais que um deslocamento geográfico, pois implica a aprendizagem do homem a respeito de si mesmo, 
do autoconhecer-se e do conhecer o outro, e faz surgir diante de nossos olhos a natureza contraditória do gênero humano. Quando as personagens centrais de A Jangada de Pedra iniciam suas andanças pela Península, elas abrem a possibilidade da descoberta de si mesmas e do outro. Cada uma delas aprende com a outra a sentir e agir de um modo diferente daquele como agiam no início da narrativa, caracterizando-se, assim, como personagem do romance, que, segundo Bakhtin, "deve ser apresentado não como algo acabado e imutável, mas como alguém que evolui, que se transforma, alguém que é educado pela vida" (BAKHTIN, 1998, p.402).

A viagem, empreendida pelas personagens, mantém, em um primeiro momento, o sentido literal da palavra: realiza-se o deslocamento geográfico de um lado a outro da Península Ibérica. Contudo, o acúmulo de experiências, a convivência de uma personagem com a outra e a relação que elas mantém com o meio por onde transitam implica um outro tipo de viagem, uma interior, psicológica, que faz com que se modifiquem no decorrer da narrativa:

mas aqui veremos uma demonstração da ductilidade do espírito humano, ainda não há muitos dias, Maria Guaivara rejeitou, sem ambages, a idéia de dormirem numa casa desocupada, a lição ainda ecoa nos ouvidos de quem teve a lembrança, e agora, tanto pode a necessidade, vai Maria Guaivara condenar uma vida inteira de limpidez moral, prouvera que ninguém lhe lance em rosto a relaxidão, Não o compraremos, roubamo-lo, estas foram as palavras (SARAMAGO, 2001, p. 234-5).

Como podemos perceber, neste caso, a convicção de uma das personagens cai diante de uma situação a que ela foi exposta. O curso da viagem a altera, modificando-lhe os pensamentos e os sentimentos. Cada uma delas acumula experiências que as transforma, seja pondo em cheque suas próprias convicções, seja por tomar conhecimento de outras sensações. Podemos citar aqui a sensação de José Anaiço ao encontrar Joana Carda pela primeira vez. A cada momento da narrativa, os viajantes experimentam um tipo de sentimento: amizade, amor, raiva, ciúme, compaixão, etc. De forma que o percurso da viagem é aquele em que o caminhante "se perde e encontra, forma e transforma. E pode até mesmo reencontrar-se, transfigurado em outro de si mesmo" (IANNI, 2000, p. 27).

\section{III}


Em determinado momento da narrativa a Península corre o risco de se chocar contra os Açores. O medo da população é marcante. A catástrofe prenunciada não acontece, mas só a possibilidade disso é capaz de transtornar o cotidiano de quem mora por estas paragens.

\begin{abstract}
Sente-se o medo a crescer como uma negra sombra, o pânico é uma inundação a procura dos pontos fracos do dique, roendo o enrocamento profundo, finalmente saltou, e as pessoas que até aí tinham se mantido mais ou menos aquietadas nos lugares onde haviam assentado arraiais, começaram a mover-se para o leste, compreendendo agora que estavam perto de mais da costa, apenas setenta, a oitenta quilômetros, representava-se-lhes na imaginação que as ilhas iriam rasgar a terra até ali, e o mar invadir tudo, o cone do Pico um fantasma, e quem sabe se, com o choque, o vulcão não entraria em atividade (SARAMAGO, 2001, p. 230).
\end{abstract}

A narrativa tem uma estrutura muito semelhante a do Apocalipse de São João, onde se anuncia o fim do mundo e o surgimento de uma Jerusalém celestial. Nela, vez por outra, alude-se a figuras míticas, como o cão de Cerbère, que na mitologia grega era um cão horrendo com múltiplas cabeças que impedia que os vivos entrassem no Tártaro e que os mortos de lá saíssem. Este cão monstruoso pode simbolizar tanto "o terror da morte entre aqueles que temem os Infernos", quanto "a própria morte e o inferno interior de cada ser humano" (CHEVALIER e GHEERBRANT, 1998). Ora, no romance, as terras do sul da Europa que, catastroficamente, desligam-se do Velho Continente, são o próprio inferno: "Mas este cão, graças a Deus, não é dos que se acomodam às situações, a prova é que de um salto, galgou o abismo, com o perdão do evidente exagero vocabular, e achou-se do lado de aquém, preferiu as regiões infernais..." (SARAMAGO, 2001, p. 18). E é esse mesmo cão que servirá de guia para os viajantes e anjo da guarda em momentos de perigo. A caracterização do cão é paradoxal, ele é ao mesmo tempo o bem e o mal, o anjo protetor dos viajantes e a criatura infernal que guarda as portas do inferno: "Este cão, se considerarmos tudo quanto fez até hoje, mereceria o título de anjo-da-guarda, apesar das constantes insinuações que continuam a ser feitas sobre a sua pretensa origem infernal" (Idem, p. 250).

Tal como em uma narrativa apocalíptica, o movimento das personagens é circular, o destino da caminhada, aparentemente incerto: “...até agora parecia-lhes terem viajado 
dentro de um nevoeiro, ou, adequando esta situação particular às circunstâncias gerais, tinham sido como antigos e inocentes navegantes, no mar estamos, o mar nos leva, para onde nos levará o mar" (Idem, p. 133). A analogia com o mar parece nos remeter para a situação geral do romance. Os viajantes deslocam-se de um ponto a outro da grande jangada de pedra, sabendo vagamente porque fazem isso. Os motivos para a continuidade da viagem aparecem aleatoriamente, no momento em que esta parece estar chegando ao fim, de modo que eles não parecem ter muita ligação um com outro. Mas parece possível pensar que tudo isso integra a um movimento maior dentro dessa narrativa: os viajantes estão vivos, esse é o principal motivo que os mantém em movimento, de forma que a única certeza é a de que todos morrerão um dia, outros nascerão e ocuparão o lugar dos que se foram e, assim, sucessivamente, de modo que a vida manterá seu curso. Dessa forma, a viagem dentro da viagem, que é a das cinco personagens citadas, mostra-nos o homem em relação à vida e seus ciclos: “...há um milhão e quatrocentos mil anos viveram neste lugar homens e mulheres que fizeram homens e mulheres que fizeram homens e mulheres, destino, fatalidade, até hoje..." (Idem, p. 81).

Essa narrativa de tom catastrófico, visionário e profético dá a impressão de que $A$ Jangada de Pedra representa a própria vida, a caminhada do ser humano por sobre a terra. A história, marcada pelo fato insólito de desligamento de uma grande massa de pedra de um continente e seu deslizar pelas águas do Atlântico que mais parece prenunciar o fim do mundo, vai, ao termo da narrativa, dar a sensação de um novo início. A troca do carro "Dois Cavalos", por exemplo, por um meio de transporte mais rudimentar pode remeter para um retrocesso temporal, uma fase de transição no romance que se conclui com a chegada das personagens ao lugar onde a Península se desligou da Europa. Ali, elas se sentem como tivessem chegado ao limiar da existência: "Pedro Orce gritou, exaltado, numa jubilosa dor, É o fim do mundo, repetia as palavras de Joana Carda, repetiam-na todos" (Idem, p. 282). Numa perspectiva circular, chegar ao fim é reiniciar. Assim, podemos pensar que com a morte de Pedro Orce e a gravidez de todas as mulheres da Península temos o fim de um ciclo e o início de outro. E o caráter inacabado desse romance dá-nos a idéia de que a vida irá continuar seu rumo, no qual o futuro é desconhecido. Deste modo, a viagem de A Jangada de Pedra não é apenas territorial, mas representa o movimento da própria existência do ser humano. E a vara de negrilho com que se inicia a narrativa surge 
também em seu final de modo que o "fim e o começo encontram-se no mesmo ponto, na conclusão e continuidade de um tempo mítico" (REBELO, 1993, p. 35).

\section{Referências bibliográficas}

BAKHTIN, Mikhail. Questões de literatura e estética. - A Teoria do Romance. São Paulo: Unesp, 1998.

CHEVAliER, J., GHEERBRANT, A. Dicionário de Símbolos (mitos, sonhos, costumes, gestos, formas, figuras, cores, números). 12. ed. Rio de Janeiro: José Olympio, 1998.

COSTA, Horácio. "La novela portuguesa en los años ochentas: José Saramago", in: Mar Abierto. México: Fondo de Cultura Económica, 1998.

IANNI, Octávio. “A metáfora da viagem”, in: Enigmas da Modernidade. Rio de Janeiro: Civilização Brasileira, 2000.

LOPONDO, Lilian. “O Proselitismo em questão: o processo de reconhecimento em $A$ Jangada de Pedra", in: Saramago Segundo Terceiros (LOPONDO, Lilian, org.). São Paulo: Humanitas, 1998.

LUKÁCS, Georg. A Teoria do Romance (José Marcos Mariani de Macedo, trad.). São Paulo: 34, 2000.

PERRONE-MOISÉS, Leyla. "O Evangelho Segundo Saramago”. In: José Saramago - uma homenagem. (BERRINI, Beatriz, org.). São Paulo: Educ, 1999.

REBELO, Luís de Sousa. "A consciência da história na ficção de José Saramago", in: Vértice 52, jan-fev de 1993.

SARAMAGO, José. A Jangada de Pedra. São Paulo: Companhia das Letras, 2001, $15^{\text {a }}$ reimpressão.

SEIXO, Maria Alzira. Lugares de Ficção em José Saramago - o essencial e outros ensaios. Lisboa: Imprensa Nacional - Casa da Moeda, Temas Portugueses, 1999. 